\title{
Productivity Is a System Property and Need Not Decrease with the Age of the Workforce
}

\section{Thomas Lindh*}

When we try to answer the question of what an ageing work force will mean for the future European productivity growth, we actually have to start with the question about what productivity is. We often use this concept in a rather loose sense, as a generally good thing, but when we want to be more specific there are actually a host of difficult questions thatS arise. We are all well aware that productivity growth measures like Total Factor Productivity (TFP) growth are residuals of output which measure growth after accounting for changes in input factors. In the specific case of TFP growth we refer to the value-added residual change produced after accounting for changes in labour and capital inputs. Metaphorically we call this measure "technological change" although Robert Solow's original designation as a "measure of our ignorance" is actually much more appropriate.

What we want to measure when we refer to productivity is something like the capacity to produce more output with less input. In our simple abstract models we identify output with the quantity produced of some homogeneous good using two homogeneous inputs, capital and labour. But as Alexia Prskawetz showed the aggregation of the actually age-heterogeneous labour input and the effect of ageing is crucially dependent on the substitutability of the components, and Ross Guest showed how the composition of output and its change with changing demand patterns as the population ages also has an effect on the productivity growth that we can measure. Thus we are not really referring to quantity or volume measures but to value measures which are inherently dependent on the specification of technology and demand. As inter alia Dale Jorgensen has demonstrated we can by careful disaggregation account for most of the TFP residual by changes in the composition of inputs and outputs.

Thus productivity is really a system attribute rather than a property in the individual inputs. In particular it may be quite misleading to talk about individual productivity and age productivity profiles. My own and Bo Malmberg's paper points out that at plant level the measured labour productivity for the older part of the work force will tend to be lower simply because the matching process on the labour market leads to the fact that older workers will work predominantly in older plants, using older capital associated with older technologies. Axel BörschSupan pointed out for us that individual comparisons of productivity are marred

\footnotetext{
* Thomas Lindh, Institute for Futures Studies, Stockholm, Sweden. Box 591 SE-101 31 Stockholm, Sweden. Email: thomas.lindh@framtidsstudier.se
} 
by a selection bias, since a typical career means that the best workers in general change their type of work, so when we compare young workers with older workers doing the same type of work we in general will have a selection bias.

But then we can also observe that much of the action in productivity growth at the plant level as well is driven by the relation between inflows of new plants and outflow of old plants, making selection bias operative also at this level. Already Adam Smith noted that specialisation was very important for productivity making the extension and density of markets an important factor. Hence we also have to consider the scale of the system when we talk about productivity. There are important differences whether we talk about the plant level, the industry level, the national or global level, since also comparative advantages and how we organise trade and factor flows will be important for the actually observed productivity.

To summarise this formally we use simple tractable abstractions, where the typical setup starts with an aggregate production function where output $Y=f(K, L)$, and where productivity is determined by the functional form of $f($. $)$ and how we combine capital $K$ and labour $L$. In the old Capital Controversy in the 1960s it was already clear that this cannot be taken as any exact description of the actual production system and Solow and other proponents of the aggregate production function freely admitted that. Both capital and labour are value-weighted aggregates of a great number of fundamentally different humans, objects and services, which in practice are combined in a great number of ways in order to produce an ever vaster array of goods and immaterial services. Marginal products and price setting determines what is actually produced. In ideal circumstances competitive markets will equalise marginal products and prices but in the real world there is a host of imperfections, missing markets and incomplete information, making more or less persistent deviations from this ideal a fact of life. In the context of age productivity the existence of seniority wage schedules where actual wages deviate from the marginal productivity is one of the difficulties that we have no clear resolution of.

The consequences of all this fuzziness and heterogeneity is that we can have no hope to achieve a detailed true specification allowing us to logically deduce what will happen as the work force is ageing. Individual productivity cannot be separated from its social context. The measurement and information about how cognitive abilities change over the life cycle is both interesting and very worthwhile to pursue in order to give us one important piece of information. But this does not clinch the issue of whether an ageing work force will be more or less productive. Ageing will, however, have further consequences than a changing composition of individual cognitive abilities, forcing us to learn more about how social institutions and non-market activities affect the measurable output. We started this conference by considering how economic activity affects climate change and whether households or individuals are the relevant levels of analysis for this. But climate will in turn affect also economic activity and household formation and its functions are intimately tied to demographic changes. 
How future productivity will develop with ageing will remain a question of how to develop reliable forecasting models. Theory can inform the choice of model but not determine how well it actually forecasts. That remains an empirical question and one which we pursued in the previous symposia in Hawaii and at Krusenberg.

I think this symposium has illustrated that a priori reasoning actually is of little help in determining how productivity will develop with an ageing work force. Empirical investigation of the facts at several different levels and systematic evaluation of the forecasting performance of different types of models are the ways in which we can make progress in resolving these issues. One outstanding question will then be the evaluation criteria we use for the choice of forecasting models. While important, accuracy of forecasts is only one issue, because long-term forecasts of productivity change will necessarily inspire policy changes that change the relations on which the forecasts hinge. Relevant policy responses require an understanding of the underlying mechanisms, but it is well known that good forecasting models rely on inert statistical relations rather than detailed specification of all relevant channels. How should we then combine these objectives? Or should we even try? 